\title{
A ética como um princípio da justiça: uma abordagem transdisciplinar na escola
}

\author{
Luiz Síveres ${ }^{1}$ \\ https://orcid.org/0000-0003-4735-6066 \\ Lucicleide Araújo de Sousa Alves ${ }^{2}$ \\ https://orcid.org/0000-0002-2019-459X \\ Olzeni Leite Costa Ribeiro ${ }^{3}$
}

https://orcid.org/0000-0002-0571-9095

\section{Resumo}

Compreender a ética como um princípio da justiça, em um processo transdisciplinar educativo, é o foco desta reflexão. A experiência educacional está sendo implementada com base numa metodologia, que elegeu a ética como elemento central no percurso de desenvolvimento de crianças da educaçáo infantil. Esse procedimento foi demarcado por uma dinâmica interativa que considerou a subjetividade, a intersubjetividade e a sociabilidade, dimensóes estas que projetam a ética como um dinamismo transversal de fácil acessibilidade, quando trabalhado na espontaneidade da criança. Por isso, a finalidade é situar a ética como um princípio da justiça social, buscando compreendê-la enquanto dinamismo transdisciplinar em um projeto educacional da primeira infância. $\mathrm{O}$ pressuposto para o atendimento a essa finalidade parte da premissa de que educar para a justiça social requer uma virtude ética que seja capaz de desenvolver a consciência da dignidade humana e da transformação social. Concluiu-se, assim, que a educação infantil é um ambiente favorável para incorporar a ética no desenvolvimento das potencialidades, tendo como horizonte a formação de uma geração de jovens e adultos capazes de promover a responsabilidade para com o bem comum, construindo uma sociedade espiritualmente saudável e materialmente sustentável.

Palavras-chave: ética, justiça social, transdisciplinaridade, educação.

\footnotetext{
${ }^{1}$ Pós-doutorado em Educaçāo e Psicologia, Universidade Católica de Brasília, luiz.siveres@gmail.com.

${ }^{2}$ Doutorado em Psicologia, Universidade Católica de Brasília, lucicleide.ead@gmail.com.

${ }^{3}$ Doutorado em Educaçáo, Ideaah School, olzeni@ideaah.com.br.
} 


\title{
Ethics as a principle of justice: a transdisciplinary approach at school
}

\begin{abstract}
Understanding Ethics as a principle of justice, in a transdisciplinary educational process, is the focus of this reflection. The educational experience is being implemented based on a methodology which has chosen Ethics as the core element in the development course of children in early childhood education. This procedure was defined by an interactive dynamic that considered subjectivity, intersubjectivity and sociability - dimensions that configure Ethics as a transversal dynamism of easy accessibility once the child's spontaneity is taken into account. Therefore, the aim is to situate Ethics as a principle of social justice, seeking to understand it as a transdisciplinary dynamism in an early childhood educational project. The assumption for achieving this aim is based on the premise that in order to educate for the benefit of social justice an ethical virtue that enables the awareness of human dignity and social transformation is required. It was concluded, therefore, that early childhood education is a favorable environment for incorporating Ethics in the development of the child's potentialities, aiming to form a generation of young people and adults capable of promoting responsibilities for the common good whilst nurturing a society that is spiritually healthy and materially sustainable.
\end{abstract}

Keywords: ethics, social justice, transdisciplinarity, education.

\section{Introdução}

A temática da ética, vinculada à justiça e compreendida como uma experiência transdisciplinar, base de um projeto escolar, será objeto desta reflexão. Potencializar tal proposta é recomendado, inicialmente, percorrer a história brasileira e recordar algumas situaçóes que se revelaram extremamente ausentes da ética e da justiça. Sem entrar no mérito dos fatos, é oportuno apenas relembrar o procedimento colonizador vivenciado por séculos e, em decorrência, um período caracterizado pela escravidão e, atualmente, o fortalecimento de um sistema de extrema desigualdade social. Ou seja, a dinâmica de dependência, de subserviência e de desigualdade foram características fundamentais que marcaram a cultura nacional em toda a sua história.

Essa conjuntura foi analisada por distintas percepçóes, mas talvez a compreensão mais apropriada foi construída por Gilberto Freyre (1995), quando projetou a analogia da Casa Grande \& Senzala. Ele objetivou interpretar a realidade brasileira, revelando por um lado a sua potencialidade cultural, mas também por outro, as suas maleitas provocadas por situaçôes e sistemas injustos. Isto é, a realidade brasileira foi configurada, no decorrer de 
sua história, por uma anomalia social que beneficiava muito, a um pequeno grupo social, à custa da populaçáo empobrecida.

E no contexto atual, quando a humanidade está sendo afetada pelo Coronavírus, o país defronta-se, também, com esta pandemia viral. Mas é possível depreender, mesmo diante dessa crise, que um pequeno grupo social está se enriquecendo, ainda mais, e a grande massa de cidadãos estão sendo alijados dos seus direitos e das possibilidades de construir uma vida com mais dignidade. Essa situação continua se revelando, e de forma exponencial, com digitais cada vez mais injustas e desumanas.

Para a superação desses desafios, várias iniciativas já foram indicadas. Vários movimentos sociais, a exemplo de Canudos; muitas experiências comunitárias, como as Comunidades Eclesiais de Base; inúmeras Campanhas da Fraternidade, de forma ecumênica, como a do próximo ano que vai tratar do tema do diálogo e da fraternidade, diversas experiências educativas, como a Movimento de Educação de Base. Enfim, esses são alguns sinais de que é possível desenvolver projetos mais justos e que tenham a ética como um princípio transversal.

Este também é o propósito desta temática: contribuir com a experiência vivida em ato, aliada à reflexão da ética como um projeto de justiça social. Neste sentido, partilhamos no tópico que segue, uma experiência escolar na qual a ética é abordada como uma dinâmica transdisciplinar, tendo seus princípios aplicados de forma integrada às potencialidades humanas. Nesta experiência, destacamos a ética (MORIN, 2007b) como operador cognitivo da Complexidade numa abordagem transdisciplinar, buscando aproximar essa compreensão de uma das possibilidades de praticá-la como justiça social, influenciando os projetos educativos.

\section{A ética como experiência educativa transdisciplinar}

A força da incursão da ética à consciência está na educação. Cortella (2010, p.106), parte de uma definição que nos remete a essa percepção, quando ele concebe a ética como "a fronteira entre o que a natureza manda e o que nós decidimos", situando-a entre as competências que orientam, a saber, "decidir, julgar, avaliar".

E ao falar de competências evocamos habilidades, alcançamos os processos de aprendizagem, aportamos na educação, pois a educação religa espaços de vivências que envolvem elementos de origem, tais como grupo, relação, socialização, estar junto, o 'eu' e os outros. Nesta linha de raciocínio, 
identificamos um aspecto que nos inspirou a chamar de o 'ponto de Arquimedes': assimilar a ética não como um valor que está para um (indivíduo), mas para muitos (sociedade). Logo, é o bem individual aplicado ao bem comunitário. Portanto, em se desenvolvendo na consciência, leva-nos a mover o mundo para o lugar de conforto, a "moradia saudável, materialmente sustentável, psicologicamente integrada e espiritualmente fecundada” (BOFF, 1997, p. 32). E para isto, defendemos que a alavanca que mantém a ética emersa na consciência, está nas potencialidades do indivíduo.

Se somos éticos quando aplicamos e usufruímos daquilo que faz bem e é saudável ao grupo, à comunidade, então, para sermos éticos temos de dar aos outros aquilo que temos. Assim sendo, para chegar à consciência e transcender o discurso, a ética só se realiza como um projeto de justiça social. Aqui começa o seu sentido, enquanto experiência educativa transdisciplinar, aplicada a uma comunidade de crianças de 6 meses a 5 anos.

Reportando-nos ao público envolvido na experiência, crianças da Educação Infantil, partimos das Diretrizes Curriculares Nacionais - DCNEI, para esta etapa escolar que destacam, entre os três princípios que a embasam, o princípio ético. Ao defini-lo, o incluem no capítulo da "valorização da autonomia, da responsabilidade e do respeito ao bem comum, ao meio ambiente e às diferentes culturas, identidades e singularidades" (BRASIL, 2010, p. 16).

Porém, há um ponto que nos leva a questionar as DCNEI, principalmente, quando concentram no professor a responsabilidade de expressar o princípio ético em tempo integral. Esta premissa se configura como se a tarefa se resumisse em transferir para seus alunos uma atitude ética diante da vida. Associamos essa visão a uma crença cultural que coloca o professor como um modelo para os alunos. Trata-se de uma crença aplicada, equivocadamente, como estratégia didática de ensino, e que tende a disseminar a transmissão do conhecimento como uma relação de causalidade linear, expressa da seguinte forma: aluno vê, aluno aprende.

Isto pode até se realizar com abordagens cognitivas, quando se pratica o ensino pelo treino de fórmulas pré-estabelecidas, por exemplo. Porém, não se realiza quando precisamos atuar no campo socioemocional. E a ética é um construto do campo socioemocional, logo, uma abordagem que tem por base ensino e treino não faz nenhum efeito sobre a importância de torná-la um valor, um princípio, uma atitude, enfim, um comportamento que transcende o vocabulário (discurso) e passa a ser modulado pela consciência (atitude).

No contexto da educação infantil, consideramos como as mais eficazes linhas de abordagem da ética, aquelas que se revelam, mesmo na mente 
imaginativa das crianças, como posturas bem definidas. E se, à luz de Cortella (2010), esse princípio orienta para a capacidade de decidir, julgar e avaliar, ela deve alcançar a mente consciente. Quando o outro passa a ser um ponto focal no despertar do desejo de atuar para o bem comum, essa alavanca para a consciência se assenta naquilo que que pode ser realizado de forma recíproca.

\section{O contexto da experiência e sua relaçáo com a ótica transdisciplinar}

Ética e criança são dois mundos que não costumam se encontrar e dialogar. Isto talvez se deva a um vício histórico que atribui à figura da infância a imagem inanimada de alguém que não atingiu um grau de maturidade suficiente para participar da sociedade de forma ativa e protagonista. Por esta razão, um princípio como a ética tende a ser considerado pauta de adulto, pois criança não tem condiçóes de compreender ou absorver essa abordagem em sua formação até que atinja uma idade que supostamente se delimita para tal complexidade.

Nesse contexto da experiência educativa aqui relatada, o trabalho com a ética não se restringiu à visão tradicional de ensino que enfatiza a imitação de comportamentos do professor. Tratamos a ética como uma habilidade. Mais do que isso, a ética adquiriu o status de ser constituída como uma entre as nove macrohabilidades socioemocionais que compóem a metodologia adotada na escola. Dentro das nove, a ética está incluída e se associa, quase que de maneira intrínseca, ao primeiro grupo das habilidades pessoais que se catalisam entre si: autoconhecimento, ética, e autonomia, conforme ilustra a figura abaixo:

Figura 1: Macrohabilidades adotadas na experiência com a ética transdisciplinar 


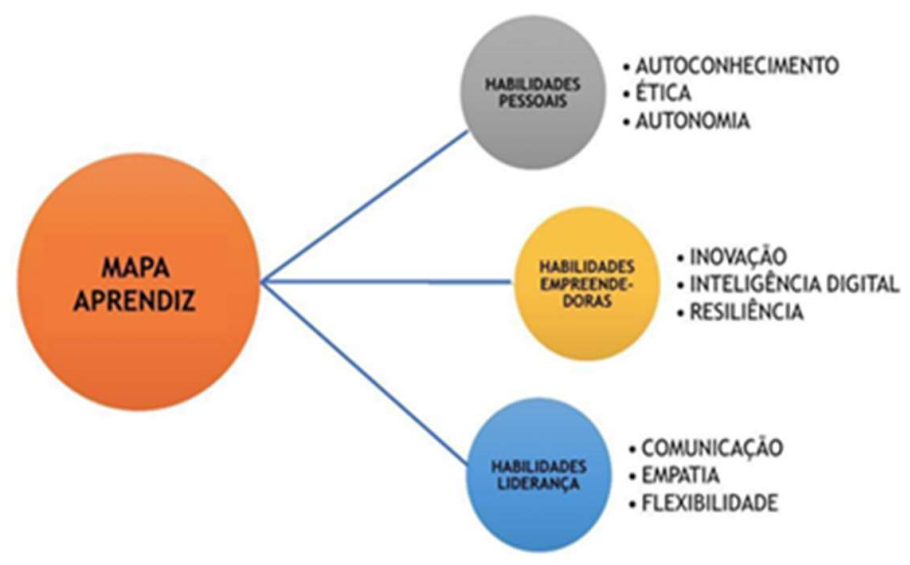

Fonte: Criada pelos autores.

Trata-se de uma escola de educação infantil, idealizada como um espaço que visa propiciar à criança viver a felicidade que emerge da aventura do aprender. Fundada em 2018, teve sua origem na concretização de uma tese de doutorado, cujo objeto de estudo consistiu em conhecer e explorar a história de vida de dez experts adultos e profissionais que quebraram paradigmas em suas respectivas áreas de atuação. $\mathrm{O}$ foco do estudo foi analisar a trajetória desses adultos, buscando, na infância, os fatores e elementos que facilitaram o perfil desbravador que, mais tarde, os transformaram em exímios colaboradores da ciência.

Existiu uma premissa central, desde o planejamento do percurso para a realização da tese, que foi defender que pessoas nascem com potencialidades natas e que, por meio da descoberta e vitalização dessas potencialidades, elas se encontram consigo e adquirem um superpoder intelectual e emocional para vislumbrar mudar o mundo. Ao reconhecer que as possui, o próximo desafio é descobrir qual delas, isolada ou associada a outras, se tornará o seu velo de ouro $^{4}$ da autorrealização, ou seja, o potencial que se tornará a grande contribuição que cada uma colocará a serviço da humanidade, dentro e/ou para além de seus domínios de atuação.

\footnotetext{
${ }^{4}$ Velo de Ouro é considerado um talismã que outorgava, a quem o possuísse, prosperidade e poder. É um termo usado para definir um navegante ousado, um explorador de mares, alguém aventureiro e que gosta de viver perigosamente.
} 
Como as cinco principais potencialidades humanas, configuramos a inteligência, a aptidão, o talento, a criatividade e as altas habilidades. Isso pode ser identificado nas crianças, ajudando-as a reconhecer em si, por meio do autoconhecimento, a potencializar o desejo de participar e ajudar o ambiente a se tornar moradia saudável para o bem comum. Permitindo-se, assim, a conduzir pela autonomia, passando a compreender como fazer isso de forma independente, impulsionadas pela autoconfiança com base naquilo que já sabem e que possuem de superpoder.

Nesse sentido, a perspectiva transdisciplinar contribui na medida em que a prática da ética extrapola o papel do professor, a centralidade em campos específicos do conhecimento, a visão de que tenra idade é uma barreira, e passa a mover-se como propulsão para abarcar diferentes horizontes. Na prática isto se desencadeou a partir das vivências das crianças em cenários criativos, para os quais foram designadas áreas essenciais humanas, por se entender que em cada um está a essência do ambiente, por meio da qual se promove o autodesenvolvimento do indivíduo que habita cada criança.

As experiências que as crianças vivenciam ao passar por circuitos sincronizados dentro destes cenários criativos, desenvolvem ao longo da jornada de aprendizagem, o senso de equilíbrio. Conforme o perfil sociocomportamental que é identificado em cada criança da escola, alguns cenários se refletirão para elas como "ambiente flow" (CSIKSZENTMIHALYI, 1996) ou como ambiente antagônico. Flow categoriza o espaço que despertará seus sentidos mais propícios ao bem-estar, ao conforto emocional e à felicidade. Neste cenário, a criança se esquece do tempo e dos ruídos ao redor ao mergulhar profundamente naquilo que é proposto como desafios de aprendizagem. Antagônico categoriza o espaço que despertará resistência, rejeição e, algumas vezes, até reaçóes mais ostensivas de negação.

Esses indicadores sinalizam e orientam para diversas características de cada criança: são as potencialidades e o que denominamos impotencialidades. Da análise desses dados são gerados relatórios de microevoluçóes, os quais nos fornecem subsídios para identificar em qual das potencialidades humanas aqui citadas, a criança demonstrou predominância. Essa observação é direcionada às suas reaçóes e comportamentos espontâneos, registrados ao longo das vivências nos cenários criativos.

Quando mencionamos o senso de equilíbrio que é desenvolvido nesses circuitos, ao integrar o prazer e o desprazer na convivência com o contraditório, já estamos explorando, com intencionalidade, uma face da ética na metodologia adotada. Trata-se de um fenômeno denominado mediania e, 
que para Cenci (2012), é o lugar no qual a razão e a inteligência prática encontram o meio-termo. $\mathrm{O}$ sentido desse conceito com relação à ética, aplicado a esta experiência educativa com as crianças, está em viver, no seu cotidiano escolar, a realidade de que as escolhas estejam de acordo com a razáo e com o desejo, ou seja, ao fazê-las é preciso pensar no que é desejável, mas também no que é certo, e que este nem sempre estará de acordo com o seu prazer. Esse é o ensinamento das duas categorias que embasam a vivência do contraditório nos cenários criativos, pois quando inserimos crianças em atividades que se orientam pela mediania, elas se deparam com açôes que são dirigidas para o equilíbrio e pelo equilíbrio.

Trazemos da obra Ética a Nicômaco (ARISTÓTELES, 1991, p. 44) que a virtude moral "é um meio-termo entre dois vícios, um dos quais envolve excesso e o outro, deficiência, e isso porque a sua natureza é visar à mediania nas paixóes e nos atos". É desse autor que deriva a concepção ética de mediania, na qual a virtude encontra e escolhe o meio-termo trazendo a harmonia. Para ele, a virtude posiciona-se sempre no meio, e os extremos indicam tendências viciadas.

Observamos que na medida em que as crianças desenvolvem alguns marcos do autoconhecimento (definidos na metodologia como falar sobre si, identificar e nomear emoçôes e sentimentos, autoavaliar-se, contar a sua história de vida, dar alguns sinais de que já demonstra consciência de si, agir com alteridade), ela reconhece em si, tanto potencialidades latentes, como manifestas.

Seguimos para o passo seguinte que é o tutor identificar a janela de acesso predominante, ou seja, aquele potencial que lhe confere um nível de autoconfiança a qual chamamos superpoder. Remetendo à mediania de Aristóteles (1991), caminhamos para identificar e trabalhar a hipertrofia, partindo da premissa de que aquilo que se tem paixão, pratica-se de forma exacerbada, desviando o foco do outro e do mundo ao redor, em virtude da alta capacidade, sobretudo na criança, de imergir profundamente, quando está diante de seu velo de ouro.

Inicia-se, neste ponto da experiência, uma abordagem intencional da ética como eixo transversal para direcionar para a conduta do bem e da virtude, aquilo que se faz de melhor. O objetivo agregado é conduzir as crianças à compreensão de que aquilo que ela faz de melhor traz subjacente um conjunto de regras compensatórias, ou seja, o dever de equilibrar o efeito de seu superpoder para neutralizar possíveis consequências negativas. O desafio será transformá-lo nos benefícios que ela pode oferecer aos outros, se colocar esse potencial a serviço da moradia saudável para o bem comum. A 
força desse elemento que aliamos ao trabalho se embasa na premissa de que o mau uso da inteligência, do talento, das aptidóes, da criatividade e até das altas habilidades, pode gerar consequências desastrosas para a humanidade. O contrário disto é levá-lo a gerar grandes transformaçôes.

O foco transdisciplinar está na mentalidade que buscamos estimular nos professores e nas crianças ao terem a liberdade de manifestar a criatividade em toda a sua plenitude, porque a mentalidade transdisciplinar está fundamentada na lógica de que existe sempre uma 'terceira possibilidade' e que as soluçôes não são dicotômicas: ou isto ou aquilo. Aí se concentra toda a força da criatividade atuando nas pessoas como ela realmente é: de forma naturalmente presente, parte de todo ser humano que pensa.

Adotamos a concepçáo de que ter um comportamento ético implica respeito, tolerância, aceitação das diferenças e pensamento crítico para distinguir entre o certo e o errado, a fim de viver bem em sociedade. A ética passou, então, a ser desenvolvida como uma das mais importantes habilidades na dimensão pessoal, ou seja, a dimensão que pode levá-la para o nível da consciência. Os circuitos pelos cenários criativos, vivenciando o flow e o antagônico, é o espaço social de relação com os outros e o ambiente do qual não podemos abrir mão, tendo em vista que não se constrói o ser ético tãosomente pelo conhecimento. Para alcançar o status da transformação de condutas, somente se trabalhada como habilidade a ser adquirida, o que, por sua vez, não ocorre se não for praticada envolvendo espírito (a consciência) e a alma (a energia do ser). Só se dá aquilo que tem, logo, para ser ético é imprescindível praticar atos éticos desde a mais tenra idade.

Desse modo, a prática da ética está, também, correlacionada à conduta do professor, já que ajuda a desenvolvê-la, a sabedoria e a orientação dos mais maduros que estáo em volta das crianças. Aqui reside a importância de falarmos em uma educação ética. A criança ética sabe viver em um ambiente social, é capaz de reconhecer e respeitar as necessidades alheias e identificar o uso de sua potencialidade para o bem comum.

Para acompanhar a criança orientando, identificando e monitorando seus comportamentos, criamos oito marcos da ética que fazem parte da metodologia. Esses marcos servem como evidências que vão se apresentando em diferentes níveis na criança, quais sejam: demonstra individualismo em suas relaçóes, começa a se interessar pelo coletivo, percebe que faz parte de um coletivo, preocupa-se com pontos de vista do coletivo, exerce a colaboração, respeita e escuta posicionamentos, reconhece o limite entre atitude e consequência, e, finalmente, identifica o uso de sua potencialidade para o bem comum. 
Os marcos foram organizados em uma escala não-linear, mas cíclica, e, por isso, não há períodos pré-fixados, como bimestre ou ano letivo, por exemplo. $\mathrm{O}$ trabalho é desenvolvido ao longo do que chamamos jornada de aprendizagem, e as evidências são registradas na medida em que são observadas, no cotidiano, aspectos negativos ou positivos.

\section{A ética como operador da Complexidade numa abordagem transdisciplinar}

$\mathrm{Na}$ experiência escolar anteriormente relatada, na qual a ética é abordada como uma dinâmica transdisciplinar, tendo seus princípios aplicados de forma integrada às potencialidades humanas, podemos constatar que a ética complexa (MORIN, 2007b) para a justiça social, convoca-nos a assumirmos a nossa condição enquanto humano, de realidade tripla, a de sermos ao mesmo tempo, indivíduo, parte da sociedade e parte da espécie para o exercício de uma cidadania planetária. Esta consciência de nossa identidade como seres pertencentes a um todo se embasaria na ética da compreensão entre as pessoas que se vincula à ética da era planetária, caracterizada pelo "pensar bem”, para se ter uma cabeça bem-feita (MORIN, 2008), para se exercer uma atuação consciente e com ciência.

A sinergia entre esses três elementos aparentemente separados, mas complementares e essenciais para uma vida perpassada pela ética, ajuda-nos a perceber a nossa dependência em relação ao meio ambiente e ao contexto em que vivemos. Visto que, enquanto humanos somos responsáveis pela sociedade que produzimos e por ela somos produzidos, numa relação consigo, com o outro e o meio.

Por isso a importância da ética em quaisquer contextos, em quaisquer níveis de ensino, para o exercício da tolerância, da compaixão, da empatia, da resistência à barbárie humana, movidos sempre por uma atitude esperançosa de que algo é possível de ser feito, de ser transformado, gerada sobre o impossível, o inesperado, o devir.

Neste sentido, não há como separar vida e conhecimento nos espaços escolares. Ambos estão imbricados e fazem parte de uma mesma realidade, a de ser e estar no mundo. Por isso, todas as açóes devem ser pensadas conscientemente, para um agir que prime pela coletividade, com "a autonomia da consciência e o sentido da responsabilidade" (MORIN, 2007b, p. 194). Assim, também primamos pela compreensão de que o conhecimento que produzimos não é separado da natureza ou desconectado de seu contexto, mas resulta das constantes interaçóes que mantemos durante a vida, com o 
mundo e com a realidade a qual pertencemos. Sem nos esquecermos de que somos uma totalidade que envolve corpo, mente e espírito, movidos não somente pela razão, mas também pela emoção.

Os espaços educativos e as práticas pedagógicas que privilegiam a religação entre a cultura científica e a humanística, resulta da ética, que consequentemente se consegue a partir de um pensar bem, e este a se desenvolver a partir de uma educação que tenha como objetivo religar o pensamento complexo e a ética. Haja vista que o pensamento complexo é o pensamento que religa, pelo exercício da ética complexa, e esta permite a ética da religação para a formação do sujeito integral e integrado, por meio de uma educação e um fazer pedagógico que se realiza, na fraternidade, no respeito e no amor, pela religação do uno (parte) e do múltiplo (todo), pelo assumir da nossa condição humana de seres dialógicos e contraditórios, possibilitando a racionalidade. Tudo isso mediado, sobretudo pelo amor e a poesia nos processos educativos, respeitando as individualidades, para o despertar das potencialidades humanas.

Sendo assim, para um jeito novo de caminhar, para processos educativos mais harmônicos e solidários há a necessidade de uma ética comprometida rumo ao humanismo planetário. Ser e pensar necessitam estar em interação constante, mediados por uma consciência ética a fim de que, professores e estudantes atuem, sem se anularem, respeitando, nos espaços educativos, as dimensóes humana, psíquica e suas antinomias.

Para tanto, requer um pensar bem, que só se adquire a partir de uma educação que busque religar o pensamento complexo e a ética. Neste sentido, a autonomia da consciência e o sentido de responsabilidade que impera no mais íntimo do espírito humano necessita de ser desenvolvido nos espaços educativos. Esta inserção contribuirá para potencializar reflexôes e autoanálises no enfrentamento das incertezas da vida, cujo dinamismo é movido por uma ecologia da ação. É, pois, neste devir que a complexidade se instaura e nela a necessidade da ética complexa para gerar, em conjunto, uma nova ordem regeneradora.

Morin (2007a) aponta, portanto, a importância de uma reforma no pensamento, para uma melhor compreensão da vida, de si mesmo e do outro. E sugere o pensamento complexo como uma das vias para superação da visão míope, do antidiálogo, de contextos injustos, como anteriormente configurados, da falta de tolerância para com o outro, ainda táo presentes nos contextos educativos de ordem local e global. Haja vista que a lógica do pensamento complexo consiste em estabelecer as conexóes e as pontes necessárias entre os vários saberes, no sentido de possibilitar as articulações 
para a obtenção de um conhecimento transdisciplinar, ou seja, de uma postura mais ética e de valorização da vida.

O pensamento que se desenvolve a partir da epistemologia complexa, mediado por uma ética como um princípio da justiça, numa abordagem transdisciplinar, passa a compreender e a respeitar a diversidade de opinióes sobre uma mesma realidade, visto que assumir uma postura transdisciplinar requer o acolhimento das multirreferencialidades. A epistemologia transdisciplinar é aberta, inclusiva e permite a construção de conhecimentos a partir do estabelecimento de pontes entre as várias áreas do conhecimento e náo apenas sob a releitura da vida, dos processos de ensino e aprendizagem sob ótica única de pensamento e compreensão.

Como ensina Morin (2010), tudo deve estar integrado, para permitir uma mudança de pensamento, uma formação para além da fôrma e que permita aos professores e estudantes no processo de ensinar e aprender a estarem em um constante processo de fazer-se e refazer-se, a partir de açóes e interaçốes intersubjetivas com o outro e os "outros". Neste sentido, experiências pedagógicas que tem em seu bojo a Teoria da Complexidade e da Transdisciplinaridade, permitem uma visão mais integrada e uma mudança de pensamento. A formação passa a ser uma ação de constituição da própria forma de ser, de viver, de relacionar-se e de agir, para um projeto educativo, a partir de uma proposta concebida por um jeito novo de caminhar, perpassado, sobretudo, por uma ética como justiça social, para uma vida social mais justa.

\section{A ética como justiça social}

A ética é uma experiência humana e sempre esteve presente no projeto histórico da humanidade. Embora essa dinâmica possa ser percebida na formação do caráter de cada pessoa ou na formatação dos costumes das distintas sociedades, ela se manifestou ou se revelou mais necessária nos períodos nebulosos, nos ambientes sombrios ou nos sistemas ameaçadores da dignidade humana ou da convivência social.

Tal realidade foi muito bem percebida pelo poeta Carlos Drumond de Andrade, que na poesia: "A noite dissolve os homens", manifestou sua preocupação com esses contextos civilizatórios que fizeram da "noite" a condição de sua existência. Daí a exclamação poética: 
E nem tampouco os rumores,

Que outrora me perturbavam.

Diante desse cenário é oportuno que as pessoas ou os grupos sociais possam acender uma luz para poder iluminar a cegueira ideológica, possam visualizar novamente os irmáos, consigam escutar os cantos de esperança, e se disponham a acolher o rumor das crianças brincando. Nesse sentido a ética é sempre a esperança de uma nova aurora, embora seus reflexos sejam tênues e seus luzeiros sejam frágeis, mas a crença dessa potencialidade emerge, novamente, para a profecia poética que desafia a humanidade, com sua história de esperança, acolhendo de forma individual ou coletiva a:

Aurora,

Entretanto eu te diviso tímida,

Inexperiente das luzes que vais acender,

E dos bens que repartirás com os homens.

Iluminados por essa energia poética é possível entender que o percurso civilizatório, principalmente, na temporalidade histórica que se iniciou com a sistematização da ética, cujo espaço embrionário estava localizado na Grécia, em torno do século VI a.C., permitiu compreender a ética como um princípio inerente à condição humana. Nesse sentido, esse percurso fazia parte do seu processo reflexivo e do seu procedimento operacional.

Embora se tenha consciência de que todos os povos, em todos os tempos e em todos os contextos históricos tenham tido uma referência ética, foi com a experiência da sistematização da filosofia grega que a ética também foi sendo sistematizada e proposta como um pressuposto da condição existencial e dos sistemas sociais. E, naquela época, um dos aspectos mais evidenciados que precisou ser iluminado, foi o contexto de injustiça.

Portanto, nesse laboratório filosófico da cultura grega, distintas abordagens sobre a ética foram explicitadas, mas aqui se propóe recuperar a proposta que compreende a ética como uma virtude que precisa ser vivida conforme a justiça. O pressuposto afirmativo de que a "ética é justiça" está ancorado no enunciado proclamado por Aristóteles (2004, p. 103), no sentido de que "a justiça é aquela que disposição de caráter que torna as pessoas propensas a fazer o que é justo, que as faz agir justamente e a desejar o que é justo". Nesse enunciado se estabeleceu, no entanto, a configuração da ética como expressão da virtude e do caráter pessoal, bem como do desejo e da prática social, a partir do exercício da antropoética (MORIN, 2007), que consiste em não desejar ao outro o que não se deseja para si mesmo. 
Considerando a filosofia aristotélica de que a justiça encerra todas as virtudes e, na sequência histórica, além da justiça integrar um princípio ético, outros atributos foram a ela incorporados e, com esse intuito, foram criadas várias adjetivaçóes, tais como a justiça comutativa, corretiva, distributiva ou normativa. Tais adjetivos procuraram, de uma forma ou outra, responder à síntese da ética entendida como justiça, porque estaria sendo compreendida, segundo Pegoraro (1995, p. 127), como um "princípio objetivo de respeito à ordem cósmica e como virtude subjetiva que leva o homem ao respeito de si, do semelhante e de toda a natureza"

Tendo como referência estes enunciados, bem como, o reconhecimento do princípio ético, no século passado vários documentos da Igreja Católica, com base no enunciado bíblico e na percepção da realidade, apontaram para a necessidade em consolidar o conceito de justiça social, e que o mesmo deveria permear as estruturas sociais. Por isso, segundo Pegoraro (1995, p.110), “a justiça sintetiza toda a qualidade humana subjetiva que aparece na prática das virtudes morais (subjetivas) e comanda todas as açóes em relação ao convívio social (objetivo) ". Com base nesse enunciado o autor indica para uma vida social justa, ou para uma justiça social, que seria a criação de uma ordem social onde a cidadania seja plena e universal.

Tal proposição foi introduzida, também, na Constituição Federal e no artigo 170, onde proclama-se que "a ordem econômica, fundada na valorização do trabalho humano e na livre iniciativa, tem por fim assegurar a todos existência digna, conforme os ditames da justiça social” (BRASIL, 1988). Portanto, a justiça social é a percepção mais importante para possibilitar educaçáo e uma vida digna para todos, consubstanciando a cidadania plena para todos.

Com base no pressuposto da justiça social, que pressupóe um empenho na defesa da dignidade de vida dos cidadãos, na proposição de estruturas sociais equitativas, e numa relação responsável e sustentável com o meio ambiente, vários projetos poderiam ser sugeridos, mas aqui está se propondo um projeto educativo que tenha como princípio a ética, que integra a articulação entre o subjetivo e objetivo, o caráter e o costume, a virtude e a prática.

Objetivando formar pessoas e construir estruturas sociais justas, tendo como princípio desencadeador a ética, o processo educacional precisaria inserir nos seus conceitos e nas suas práticas, dinâmicas compatíveis com essa finalidade. Diversas indicaçóes poderiam ser sugeridas, mas, segundo Síveres (2009), para educar para a justiça social sugere-se considerar a singularidade e 
a transversalidade da ética dentro de um procedimento que incorpora a subjetividade, a intersubjetividade e a sociabilidade.

\section{Conclusáo}

Educar, tendo como princípio transversal a ética e como finalidade formar pessoas justas e construir sistemas justos, pressupóe compreender o ser humano dentro da percepçáo da sua subjetividade que, no contexto atual, precisaria contemplar, de forma interativa, a singularidade de cada indivíduo e suas características relacionais, desenvolver o exercício da razão e a vivência da emoção, exercitar os talentos pessoais e as habilidades sociais e uma dialógica comprometida com o outro. Enfim, a ética como um princípio que ajuda a formar o caráter e configurar o costume, precisaria estar presente em todos os projetos educacionais.

A educação, além de acolher a subjetividade de cada indivíduo, tem como missão acolher a diversidade revelada pela origem familiar, pela condição social ou pela dinâmica cultural. Mas, além de acolher essas manifestaçóes, o espaço educativo é apropriado para desencadear dinâmicas intersubjetivas, que no contexto atual são recomendadas, por meio de um processo integrativo, articulando a diversidade de conexôes culturais, as distintas relaçóes pessoais e sociais, bem como, as várias formas de se vincular com o transcendente. Seria, portanto, atribuição da educação, acolher a diversidade individual e potencializar a intersubjetividade relacional.

O processo educativo sempre foi considerado, desde a época dos gregos, um projeto social. Embora tenha se vinculado, muitas vezes, a educadores ou a instituições, fundamentalmente, buscava-se contribuir com a formação das pessoas e com o desenvolvimento da sociedade. Para esse procedimento é fortemente postulado, recuperar a ética como um dinamismo transversal do percurso educacional, no sentido de promover a responsabilidade para com o bem comum, conferindo à educação um caráter público segundo os critérios da justiça social.

Enfim, para compreender a educação como um projeto que tem como inspiração a ética, além de outros aportes, sugere-se integrar a subjetividade, fomentar a intersubjetividade e desenvolver a sociabilidade, objetivando promover a justiça social. Tais possibilidades, embora identificadas de maneira autônoma, fazem parte de uma tessitura que vai configurando o tecido educacional, objetivando contribuir com uma conduta pautada na dignidade humana, na solidariedade social e na cidadania planetária. 


\section{Referências}

ARISTÓTELES. Ética a Nicômaco; Poética / Aristóteles; seleção de textos de José Américo Motta Pessanha. — 4. ed. — São Paulo: Nova Cultural, 1991. - (Os pensadores; v. 2).

ARISTÓTELES. Ética a Nicômaco. 6. ed. Tradução: Torrieri Guimarães. São Paulo: Martin Claret, 2004.

BOFF. Leonardo. A águia e a galinha: uma metáfora da condição humana. Petrópolis, RJ: Vozes, 1997.

BRASIL. Constituição. Constituição da República Federativa do Brasil. Brasília, DF: Senado, 1988.

BRASIL. Ministério da Educação. Secretaria de Educação Básica. Diretrizes Curriculares Nacionais para a Educação Infantil / Secretaria de Educação Básica. - Brasília: MEC, SEB, 2010.

CENCI, Angelo Vitório. Aristóteles e a educação. Belo Horizonte: Autêntica, 2012.

CORTELLA. Mario Sergio. Qual é a tua obra?: inquietaçôes propositivas sobre gestão, liderança e ética. 9ed. - Petrópolis, RJ, Vozes, 2010.

CSIKSZENTMIHALYI, Mihaly. Creativity: flow and the psychology of discovery and Invention. New York: Harper Collins Publishers, 1996.

FREYRE, Gilberto. Casa-Grande \& Senzala: formação da família brasileira sob o regime da economia patriarcal. Rio de Janeiro: Record, 1995

MORIN, Edgar. Introdução ao pensamento complexo. Porto Alegre: Sulina, 2007a.

MORIN, Edgar. O método 6: ética. 3. ed. Porto Alegre: Sulina, 2007b.

MORIN. A cabeça bem-feita: repensar a reforma, reformar o pensamento. Rio de Janeiro: Bertrand Brasil, 2008.

MORIN, Edgar. Os sete saberes necessários à educação do futuro. 2. ed. Brasília: UNESCO, 2010.

PEGORARO. Ética é justiça. 7. ed. Petrópolis, RJ: Vozes, 1995. 
SÍVERES, Luiz. Educação e justiça social. In: OLIVEIRA, J.L.M; SÍVERES, L. (Orgs.) Ensaios sobre justiça social. Refazendo o caminho da vida e da paz. Brasília: Editora Universa, 2009. p. 63-85.

Recebido em: 19 ago. 2020

Aceito em: 17 dez. 2020 